Recepción: 19 / $11 / 2018$

Aceptación: 28 / 12 / 2018

(9) (1)(-)

Ciencias de la salud

Publicación: 20 / 02 / 2019

Artículo de revisión

\title{
Prevención frente la presencia de infecciones respiratorias que sufren los adolescentes
}

\section{Prevention in the presence of respiratory infections suffering adolescents}

\section{Prevenção na presença de infecções respiratórias que sofrem adolescentes}

Andrea Marina Arteaga-Acuria ${ }^{\text {I }}$ andreita_arteagaa@hotmail.com

Estefania Carolina Ruilova-Mera ${ }^{\text {II }}$ stefkroly-rm@live.com

Hugo Andres Fernandez-Cedeño III hugofernandez_90@hotmail.com

Jonathan Javier Plaza-López ${ }^{\text {IV }}$ j-plaza87@hotmail.com

Liricis Yamara Zambrano-Loor ${ }^{\mathrm{V}}$ liricisyamara@hotmail.com

Narciza Paulina Briones-Bermeo VI narpauli2011@hotmail.com

Correspondencia: andreita_arteagaa@hotmail.com

Médica Cirujana; Hospital de Especialidades Portoviejo; Área de Medicina Interna; Médico General en Funciones Hospitalarias; Portoviejo, Ecuador.

Médica Cirujana; Hospital IESS; Médico General en Funciones Hospitalarias; Manta, Ecuador.

Médico Cirujano; Hospital Verdi Cevallos Balda; Médico General en Funciones Hospitalarias; Portoviejo, Ecuador. Médico Cirujano; Hospital IESS; Médico Tratante del Área de Hemodiálisis; Residente Jefe de Guardia en Área de Emergencia; Manta, Ecuador.

Magister en Emergencias Médicas; Licenciada en Enfermeria; Docente de la Universidad Tecnica de Manabí; Portoviejo, Ecuador.

Magister en Emergencias Médicas; Licenciada en Enfermeria; Docente de la Universidad Tecnica de Manabí; Portoviejo, Ecuador. 


\title{
Resumen
}

Las infecciones respiratorias que sufren los adolescentes, son un complejo grupo de enfermedades producidas por diferente etiología ya sea bacteriana, viral, etc., que afecta la estructura del aparato respiratorio a cualquier nivel. Se ubican entre las 10 principales causas de defunción en la población, no solo están presentes en el adulto, sino también en la etapa de la niñez y adolescencia, es de vital importancia darle un manejo prioritario a estas patologías ya que son un problema de salud pública. La adolescencia es considerada una etapa de buena salud, pero, es un periodo de gran interés ya que de él depende el desarrollo y la producción futura de los países, y siendo en este periodo donde se desarrollan conductas que incidirán en la carga global de enfermedad en los adultos. La pobreza e inequidad en la que viven muchos de los adolescentes, los lleva a la marginalización y la violencia y esto tiene implicancias en la salud, puesto que no son alcanzados por los programas de cuidados pediátricos ni los de adultos, tampoco cuentan con servicios de atención específicos para su edad, especialmente en el primer nivel de atención en donde se pueda promover estrategias de prevención y promoción focalizados a sus necesidades y en conjunto con otras instituciones comunitarias. Es obligación de los Estados reconocer las necesidades de salud y de desarrollo específico de los adolescentes y las personas jóvenes, así como sus derechos, Es importante el fortalecimiento de los programas de educación en salud, el uso adecuado de antimicrobianos, la actividad física y la nutrición también ayuda a mejorar la salud antes de que los adolescentes se conviertan en padres. Es de gran importancia prevenir la enfermedad por medio de tratamientos, terapias respiratorias y programas de vacunación lo que permitirá disminuir en gran medida las tasas altas de mortalidad a causa de las IRA.

Palabras claves: Infecciones Respiratorias; Adolescentes; Pobreza e Inequidad; Educación en Salud, Programas de Vacunación.

\begin{abstract}
The respiratory infections suffered by adolescents are a complex group of diseases produced by different etiology, whether bacterial, viral, etc., which affects the structure of the respiratory system at any level. They are among the 10 leading causes of death in the population, not only are present in the adult, but also in the stage of childhood and adolescence, it is vitally important to give priority to these pathologies as they are a health problem publish. Adolescence is considered a stage of good health, but, it is a period of great interest since it depends on the development and future production
\end{abstract}


of the countries, and being in this period where behaviors that will affect the global burden of disease are developed in adults. The poverty and inequality in which many of the adolescents live, leads to marginalization and violence and this has implications for health, since they are not reached by the pediatric or adult care programs, nor do they have health services. specific attention for their age, especially in the first level of care where they can promote prevention and promotion strategies focused on their needs and in conjunction with other community institutions. It is the obligation of States to recognize the health and specific development needs of adolescents and young people, as well as their rights. It is important to strengthen health education programs, the adequate use of antimicrobials, physical activity and Nutrition also helps improve health before adolescents become parents. It is very important to prevent the disease through treatments, respiratory therapies and vaccination programs, which will greatly reduce the high mortality rates due to ARI.

Keys words: Respiratory infections; Teenagers; Poverty and Inequality; Health Education, Vaccination Programs.

\section{Resumo.}

As infecções respiratórias sofridas pelos adolescentes são um grupo complexo de doenças produzidas por diferentes etiologias, bacterianas, virais, etc., que afetam a estrutura do sistema respiratório em qualquer nível. Eles estão entre as 10 principais causas de morte na população, não só estão presentes no adulto, mas também na fase da infância e adolescência, é de vital importância dar prioridade a essas patologias, pois elas são um problema de saúde publicado. A adolescência é considerada um estágio de boa saúde, mas é um período de grande interesse, pois depende do desenvolvimento e da produção futura dos países, sendo neste período que os comportamentos que afetarão o ônus global da doença são desenvolvidos em adultos. . A pobreza e a desigualdade em que muitos adolescentes vivem, levam à marginalização e à violência e isso tem implicações para a saúde, uma vez que não são alcançados pelos programas de atendimento pediátrico ou adulto, nem têm serviços de saúde. atenção específica para a idade, especialmente no primeiro nível de atenção, onde podem promover estratégias de prevenção e promoção centradas em suas necessidades e em conjunto com outras instituições comunitárias. É obrigação dos Estados reconhecer as necessidades de saúde e desenvolvimento específico de adolescentes e jovens, bem como seus direitos. É importante fortalecer os programas de educação em saúde, o uso adequado de antimicrobianos, atividade física e Nutrição também ajuda a melhorar a saúde antes que os adolescentes se tornem 
pais. É muito importante prevenir a doença através de tratamentos, terapias respiratórias e programas de vacinação, o que reduzirá em muito as altas taxas de mortalidade causadas por IRA.

Palavras chaves: Infecções Respiratórias; Adolescentes Pobreza e Desigualdade; Educação em Saúde, Programas de Vacinação.

\section{Introducción.}

Las infecciones respiratorias agudas constituyen la causa más frecuente de morbimortalidad en el mundo, particularmente en los países en desarrollo entre las que están el catarro, faringoamigdalitis, bronquitis, asma y neumonía; es esencial que haya un control frente la presencia de un alto nivel de peligrosidad en los adolescentes causado por factores como: contaminación ambiental, tabaquismo, deficiente ventilación entre otros al no procurar un correcto cuidado estas enfermedades se vuelven repetitivas mucho más al haber la adherencia al medicamento prescrito por el médico.

La OMS estima que en 2005, unos cuatro millones de personas murieron a causa de enfermedades respiratorias crónicas debido a la exposición a los combustibles de biomasa como el mayor factor de riesgo en los países de ingresos bajos y medios. Las enfermedades respiratorias crónicas son trastornos crónicos de las vías respiratorias y otras estructuras pulmonares. Las más comunes son el asma, la enfermedad pulmonar obstructiva crónica, las enfermedades pulmonares ocupacionales y la hipertensión pulmonar, OMS, (2005).

Cientos de millones de personas sufren una enfermedad respiratoria crónica en todo el mundo. 235 millones de personas tienen asma, 64 millones de personas tienen enfermedad pulmonar obstructiva crónica (EPOC), mientras que otros millones padecen otras enfermedades respiratorias crónicas a menudo no diagnosticadas. Las enfermedades respiratorias crónicas son asesinos silenciosos, descuidados pero las principales causas de muerte. OMS, (2005).

Los principales factores de riesgo son el consumo de tabaco, la contaminación del aire (en espacios abiertos y cerrados), los alérgenos, los riesgos ocupacionales, como la exposición a productos químicos y polvos, y las infecciones frecuentes de las vías respiratorias inferiores, OMS, (2016).

Además, en la adolescencia, los intensos cambios vividos y la búsqueda de la identidad contribuyen a que muchas veces el joven se vea perdido entre una multitud de estímulos internos y externos, 
entre varias y nuevas alternativas por las que tiene que optar, necesitando ayuda de los adultos. No obstante, muy a menudo sus mensajes y demandas de ayuda, comprensión y orientación, vienen enmascaradas por una conducta agresiva o de introversión, o incluso otras de diferente índole, que despiertan respuestas en su entorno también hostiles, como de desatención. Esta dificultad de comunicación entre adultos y jóvenes también puede verse reflejada en la atención médica prestada a los adolescentes, que a su vez provoca que las principales causas de mortalidad y morbilidad en esa etapa que son, en su mayoría, potencialmente prevenibles, pasen a no recibir la asistencia debida WHO, (1999) y Ziv, et al., (1999).

Las infecciones respiratorias agudas (IRA) se ubican entre las 10 principales causas de defunción en la población general, y dentro de las 3 primeras causas de muerte entre los menores de 5 años, por lo que es un problema de salud pública. Aldana, et al., (2001).

No solo están presentes en el adulto, sino también en la etapa de la niñez y adolescencia, por lo tanto es de vital importancia darle un manejo prioritario a estas patologías ya que son un problema de salud publica siendo estas responsables de aproximadamente el $60 \%$ de la mortalidad en el mundo, especialmente en países en vía de desarrollo. Camargo \& Gutiérrez, (2010).

Se calcula que en 2015 murieron 1,2 millones de adolescentes, es decir, más de 3000 al día, en su mayoría por causas prevenibles o tratables. Los adolescentes (edades entre los 10 y los 19 años) representan aproximadamente una sexta parte de la población mundial (1200 millones de personas). OMS, (2018).

En la actualidad hay 1.200 millones de adolescentes en el mundo, lo que representa 16\% de la población mundial. Esta población tuvo su pico en 1980 y actualmente sufre un descenso en términos proporcionales que se espera que continúe hasta 2050, pero es de esperar que el número absoluto de adolescentes aumente. Asia es el continente con mayor número de adolescentes (más de la mitad del total del mundo). La proporción de adolescentes en relación al total de la población varía en el mundo, siendo casi un cuarto en África (23\%), 19\% en el sur de Asia y, 18\% en América Latina y el Caribe. UNICEF, (2016).

La mortalidad global de adolescentes es de 1,2 millones anualmente, de los cuales se estima que la mayoría corresponden a causas prevenibles 3,4 En el mundo las principales cinco causas de muertes 
entre adolescentes en 2012 fueron los accidentes de tránsito, enfermedades relacionadas con el VIH, heridas autoinflingidas, infecciones respiratorias y violencia, OMS, (2015).

La persistencia de la tos, a pesar de que habitualmente tenga escasa gravedad, genera mucha angustia en los padres y un alto consumo de recursos sanitarios (repetición de visitas, uso de fármacos de dudosa utilidad y exploraciones complementarias), en gran parte, injustificados. Por este motivo, la tos se convierte en un problema de salud ante el cual los pediatras de Atención Primaria deberemos adoptar estrategias basadas en el sentido común y en la educación sanitaria. Redondo, (2008).

La adolescencia es considerada una etapa de buena salud, pero, es un periodo de gran interés ya que de él depende el desarrollo y la producción futura de los países, y siendo en este periodo donde se desarrollan conductas que incidirán en la carga global de enfermedad en los adultos. Lloyd, C., (2005).

\section{Metodología.}

El presente articulo tiene una visión específica, cumplir con una exploración de literatura en diferentes bases de datos se hizo la revisión más próxima. Para la realización de la actual investigación, se considero, información confiable sobre trabajos figurados, versados en este tema, en los que se estudia la prevención frente la presencia de infecciones respiratorias que sufren los adolescentes, se utilizaron informaciones bibliográficas, misma que se la obtuvo de libros electrónicos, consultas electrónicas, artículos científicos y revistas.

\section{Desarrollo.}

\section{Infecciones respiratorias}

Las infecciones respiratorias agudas son un complejo y heterogéneo grupo de enfermedades causadas por diferente etiología ya sea bacteriana, viral, etc., que afecta la estructura del aparato respiratorio a cualquier nivel. Cubanos, (2006).

La adolescencia es la edad que sucede a la niñez y que transcurre desde la pubertad hasta la edad adulta. Se suele esquematizar la adolescencia en tres etapas que pueden solaparse entre sí: 
- Adolescencia temprana: abarca aproximadamente desde los 10 u 11 años hasta los 14 y se caracteriza, fundamentalmente, por los cambios puberales.

- Adolescencia media: entre los 15 y los 17 años, caracterizada sobre todo por los conflictos familiares debido a la importancia que adquiere el grupo.

- Adolescencia tardía: desde los 18 a los 21 años, caracterizada por la reaceptación de los valores paternos y por asumir las tareas y responsabilidades de la madurez. Hidalgo, (2004).

Las infecciones respiratorias agudas se definen como el conjunto de enfermedades transmisibles del aparato respiratorio que incluye desde el catarro común hasta la neumonía, pasando por la otitis, amigdalitis, sinusitis, bronquitis aguda, laringotraqueitis, bronquiolitis y laringitis, con evolución menor a 15 días y con la presencia de uno o más síntomas o signos clínicos como tos, rinorrea, obstrucción nasal, odinofagia, otalgia, disfonía, respiración ruidosa, dificultad respiratoria, los cuales pueden estar o no acompañados de fiebre. Ferreira, et al., (2013).

Las infecciones respiratorias agudas (IRA) son un complejo y heterogéneo grupo de enfermedades, causadas por distintos gérmenes que afectan el aparato respiratorio con una evolución menor a 15 días; $\mathrm{Su}$ forma más común de presentación, es la rinofaringitis aguda catarral, con la presencia de uno o más síntomas o signos clínicos como: tos, rinorrea, obstrucción nasal, odinofagia, otalgia, disfonía, respiración ruidosa, dificultad respiratoria, los cuales pueden estar o no acompañados de fiebre y que en ocasiones se complican con neumonía, bronconeumonía, bronquiectasia y absceso pulmonar a las cuales se les denomina IRA Baja. González, (2013).

Según Rodríguez, et al., (2013), realizaron un estudio titulado "Factores de riesgo para enfermedad respiratoria en población de 5 a 14 años de una localidad de Bogotá", cuyo objetivo fue la de determinar cuál era la prevalencia de las sintomatologías de estas patologías, asma y rinitis, probablemente ligados a la contaminación del ambiente aéreo.

Los AVP tanto en Uruguay como en todos los países de América Latina y el Caribe son en más del $50 \%$ de los casos, causados por accidentes y lesiones externas voluntarias o involuntarias y violentas. Si bien ambos sexos comparten estas causas en los primeros lugares, las mujeres presentan niveles más bajos de las mismas, apareciendo en este grupo poblacional otras causas frecuentes de muerte como las cardíacas, los neoplasmas y algunas enfermedades infecciosas (infecciones respiratorias y gastrointestinales). Aleman, et al., (2018). 
Estos patrones de enfermedad, ponen en evidencia la transición epidemiológica en la que se encuentra la región, que tienen como consecuencia el aumento de las enfermedades no transmisibles y las causas externas, como responsable de la mortalidad prematura. Durante la adolescencia, los patrones de mortalidad se comienzan a diferenciar de acuerdo al sexo y tal como observamos comienzan a jugar un rol central los factores ambientales y comportamentales. Viner, et al., (2011).

La pobreza e inequidad en la que viven muchos de los adolescentes en esta región, lleva a la marginalización y la violencia y esto tiene implicancias en la salud, no solo en la adquisición de conductas de riesgo sino también en el acceso al sistema de salud. Girard, (2009).

En cuanto a los antecedentes familiares, es básico preguntar por enfermedades respiratorias, en especial asma y atopia. Tendremos registrados en la historia de nuestro paciente: antecedentes perinatales, patologías previas, uso de fármacos y factores ambientales, como tabaquismo activo o pasivo, convivencia con animales domésticos y manchas de humedad. En cuanto a las inmunizaciones, la comercialización de la vacuna dTpa, que esperamos que próximamente se utilice en la revacunación de los adolescentes, permitirá minimizar la tos ferina que, en nuestro entorno, está experimentando un discreto incremento. Ridao, (2012).

En la exploración física, valoraremos la presencia de signos que indiquen atopia. Buscaremos el goteo nasal posterior, es decir, el drenaje de mucosidad en la pared posterior de la faringe, que puede acompañarse de otitis serosa, hipertrofia amigdalar y/o adenoidea o sinusitis de la zona paranasal El estridor inspiratorio es sugerente de cuerpos extraños o masas de localización en vía respiratoria alta. Más extraño será encontrar cianosis, acropaquia, tórax en barril u otros síntomas de enfermedad respiratoria crónica o enfermedades sistémicas. Ridao, (2012).

\section{Otras enfermedades infecciosas}

Gracias a las mejoras registradas en la vacunación infantil, la mortalidad y morbilidad por sarampión entre los adolescentes han descendido de manera notable, en particular, en un 90\% en la Región de África entre 2000 y 2012. La diarrea y las infecciones de las vías respiratorias inferiores figuran entre las 5 primeras causas de muerte en el grupo de 10 a 19 años. Junto con la meningitis, son las tres primeras causas de muerte de adolescentes en África y en países de ingresos bajos y medios. OMS, (2018). 


\section{Carencia de servicios específicos para los adolescentes}

Los adolescentes habitualmente no tienen servicios que respondan a las necesidades específicas. Las intervenciones para los niños habitualmente se extienden a las etapas tempranas. Sin embargo, es habitual que los adolescentes no sean alcanzados por los programas de cuidados pediátricos ni los de adultos y tampoco cuentan con servicios de atención específicos para su edad, especialmente en el primer nivel de atención en donde se pueda promover estrategias de prevención y promoción focalizados a sus necesidades y en conjunto con otras instituciones comunitarias. Aleman, et al., (2018).

La mayoría de los jóvenes goza de buena salud, pero la mortalidad prematura, la morbilidad y las lesiones entre los adolescentes siguen siendo considerables. Las enfermedades pueden afectar a la capacidad de los adolescentes para crecer y desarrollarse plenamente. El consumo de alcohol o tabaco, la falta de actividad física, las relaciones sexuales sin protección y/o la exposición a la violencia pueden poner en peligro no solo su salud actual, sino también la de su adultez e incluso la salud de sus futuros hijos. OMS, (2018).

La brecha de equidad sanitaria en y entre los países, los resultados sanitarios que corresponden a las mujeres, los niños y los adolescentes empeoran cuando se trata de personas excluidas o marginadas de la sociedad, están afectadas o perjudicadas por la discriminación o viven en comunidades subatendidas - en especial las más pobres y con menor nivel de instrucción, y las que viven en las zonas más remotas. En los países de ingresos bajos y medios puede haber: Hasta al menos 18 puntos porcentuales de diferencia entre los grupos más ricos y los más pobres de estos países en la búsqueda de atención para los niños con síntomas de neumonía, y bajas tasas de búsqueda de atención en general, OMS, (2015)

\section{Derechos de los adolescentes}

Los derechos del niño (persona menor de 18 años) a sobrevivir, crecer y desarrollarse se recogen en diversos instrumentos jurídicos internacionales. En 2013, el Comité de los Derechos del Niño, encargado de vigilar el cumplimiento de la Convención sobre los Derechos del Niño, publicó directrices sobre el derecho de los niños y los adolescentes al goce del grado máximo de salud que se pueda lograr. Asimismo, en 2016 se publicó una Observación general sobre la realización de los 
derechos de los niños durante la adolescencia. En las publicaciones se puso de relieve las obligaciones de los Estados de reconocer las necesidades de salud y de desarrollo específico de los adolescentes y las personas jóvenes, así como sus derechos. OMS, (2018).

Teniendo como punto de partida, los derechos del niño basados en la Convención Internacional de derechos del niño y el Código de Infancia y adolescencia, la búsqueda de respuestas, efectivas y eficientes, requiere una adecuada aplicación de la atención primaria en salud, que implica generar un proceso de trabajo comunitario con participación social, que lleve a la comunidad y a sus actores sociales claves a empoderarse del problema y de sus posibles soluciones, lograr un trabajo intersectorial en busca de modificar los determinantes sociales de la salud y mejorar la oportunidad y calidad en la atención de los casos, haciendo una realidad las redes integradas de servicios de salud. Ministerio de Salud y Protección Social, (2014).

\section{Prevención y tratamiento en el control de esta enfermedad}

Fomentar comportamientos saludables durante la adolescencia y adoptar medidas para proteger mejor a los jóvenes contra los riesgos sanitarios es fundamental para la prevención de problemas de salud en la edad adulta, así como para la salud futura de los países y su capacidad para desarrollarse y prosperar. OMS, (2018).

\section{Malnutrición}

Muchos niños y niñas de países en desarrollo padecen desnutrición cuando llegan a la adolescencia, lo que los hace más propensos a contraer enfermedades y morir a una edad temprana. OMS, (2018).

\section{Actividad física y nutrición}

La anemia por carencia de hierro fue la causa principal de años perdidos por muerte y discapacidad en 2015. Los suplementos de hierro y ácido fólico son una solución que también ayuda a mejorar la salud antes de que los adolescentes se conviertan en padres. Se recomienda administrar regularmente a los adolescentes un tratamiento vermífugo en aquellas zonas con presencia frecuente de helmintos intestinales, como los anquilostomas, a fin de prevenir deficiencias de micronutrientes (como el hierro). OMS, (2018). 
Desarrollar en la adolescencia unos buenos hábitos de alimentación sana y ejercicio físico es fundamental para gozar de una buena salud en la edad adulta. Asimismo, reducir la comercialización de alimentos ricos en grasas saturadas, ácidos grasos trans, azúcares libres o sal, y ofrecer acceso a alimentos sanos y oportunidades de hacer ejercicio son medidas importantes para todos, pero en particular para los niños y los adolescentes. Sin embargo, los datos de las encuestas disponibles indican que menos de uno de cada cuatro adolescentes sigue las directrices recomendadas sobre actividad física: 60 minutos diarios de actividad física moderada o intensa. OMS, (2018).

\section{Consumo de tabaco}

La gran mayoría de personas que consumen tabaco hoy en día comenzaron a hacerlo cuando eran adolescentes. Prohibir la venta de productos de tabaco a menores, subir el precio de esos productos gravándolos con impuestos más altos, prohibir la publicidad del tabaco y garantizar la existencia de entornos libres de humo es sumamente importante. A nivel mundial, al menos uno de cada diez adolescentes (de 13 a 15 años) consume tabaco, y en algunas regiones esa cifra es mucho mayor. En algunos países de ingresos altos, parece que está disminuyendo el consumo de cigarrillos entre los adolescentes más jóvenes. OMS, (2018).

\section{Difusión de programas de educación en salud}

La identificación de señales de alarma durante la Infección Respiratoria Aguda (IRA), es fundamental para disminuir el impacto de la enfermedad y la mortalidad asociada. Determinantes personales como una mayor edad y escolaridad impactan de forma positiva en los conocimientos de las madres sobre los signos de alarma de IRA. Es importante el fortalecimiento de los programas de educación en salud para el cuidado de los niños entre esta población. Domínguez, et al., (2017).

Existen antecedentes en la literatura médica sobre la utilidad de las intervenciones educativas en la población en el nivel de conocimientos sobre uso adecuado de antimicrobianos. Al respecto, se ha visto que intervenciones educativas con estrategias únicas, como la difusión de material educativo (impresos, vía informática, charlas o métodos pasivos), no mejoran significativamente el nivel de conocimientos; en cambio se ha sugerido en algunas revisiones sistemáticas que estrategias que combinen charlas, talleres interactivos y material audiovisual, focalizados a los intereses y necesidades específicas del grupo intervenido, tienen mayor impacto en el nivel de conocimientos 
de la población intervenida, lo que podría a su vez contribuir a disminuir el uso de antimicrobianos. Silva, et al., (2012).

El conocimiento sobre uso adecuado de antimicrobianos en la población es relevante para lograr un buen uso de estos medicamentos. Se evaluó el grado de conocimientos sobre uso adecuado de antimicrobianos en estudiantes de $7^{\circ}$ básico a $3^{\circ}$ medio de dos colegios municipalizados de Lo Barnechea. Luego, en uno de estos establecimientos se realizó una intervención educativa consistente en dos talleres teórico-prácticos. Se repitió la encuesta inicial al terminar la primera sesión educativa y cuatro meses después de completar la intervención. Se aplicó la encuesta de conocimientos a 489 estudiantes. El porcentaje basal de aprobación fue de 40,2\%. Luego del primer taller este porcentaje ascendió a 74,5\% (p: 0,0001); a los cuatro meses la tasa de aprobación fue de $59,1 \%$. Existen carencias importantes en el grado de conocimientos sobre uso adecuado de antimicrobianos en la población estudiada, que mejora significativamente después de una intervención educativa. Silva, et al., (2012).

\section{Estrategia preventiva}

Aunque la prescripción de antibióticos con el fin de evitar la aparición de una infección es una tentativa en la praxis clínica, son pocas y muy concretas las situaciones clínicas en las que esta estrategia se ha documentado como beneficiosa y recomendable. La profilaxis antimicrobiana se basa en la utilización de antibióticos en ausencia de infección para prevenir el desarrollo de la misma. Existen unas premisas que deben tenerse muy en cuenta cuando se plantea esta estrategia preventiva y que permiten un adecuado balance entre el beneficio y los riesgos de la medida. Los fármacos utilizados deben: ofrecer una cobertura ajustada a los patógenos más prevalentes para cada indicación concreta, tener un espectro antimicrobiano lo más estrecho posible y utilizarse durante un periodo de tiempo breve. Marès, (2014).

Dentro de las infecciones respiratorias agudas del tracto respiratorio inferior, la neumonía tiene gran connotación por su incidencia, gravedad potencial y elevada mortalidad, por el consumo de recursos que implica y los cambios epidemiológicos de los microorganismos causantes, junto a la creciente resistencia bacteriana a los antimicrobianos. Las pruebas de laboratorio no son estrictamente necesarias en la atención primaria, donde tampoco están indicados estudios microbiológicos y la radiografía de tórax no debe hacerse de forma rutinaria. Toledo R., Toledo M., (2012). 
Ante complicaciones y otros criterios, el paciente debe ser hospitalizado para su tratamiento y control. Se recomienda tratamiento antibiótico en todos los casos, en función de la edad del paciente. La prevención es de vital importancia en el control de esta enfermedad. Se trata de una enfermedad curable que puede ser fatal, sobre todo en niños, por lo que resulta necesario conocer su importancia como problema de la salud pública y tener un conocimiento actualizado acerca de su etiología, patogenía, diagnóstico y las estrategias para su tratamiento y prevención. Toledo R., Toledo M., (2012).

La neumonía causada por bacterias puede tratarse con antibióticos. El antibiótico de elección es la amoxicilina en comprimidos dispersables. La mayoría de los casos de neumonía requieren antibióticos por vía oral los cuales suelen recetarse en centros de salud. Estos casos también pueden ser diagnosticados y tratados con antibióticos orales baratos a nivel comunitario por los trabajadores de salud comunitarios capacitados Se recomienda la hospitalización solamente en los casos graves. OMS, (2015).

La vacuna antigripal de virus vivos atenuados, cuya composición específica se modifica cada año de acuerdo con las características de los virus circulantes, tiene una eficacia del orden del 70-80\% para la prevención de la gripe del año en curso. En los niños, están indicadas las vacunas de virus fraccionados o de subunidades (no las de virus enteros, que son más reactogénicas). En los menores de 9 años que no han sido vacunados previamente, se recomienda administrar dos dosis con 1 mes de intervalo para alcanzar una mejor respuesta inmunitaria. Gonzalo de L., Méndez, (2012).

En la incidencia de neumonía adquirida en la comunidad (NAC) indeterminadas, especialmente en mayores de 4 años pueden utilizarse amoxicilina asociada o no a azitromicina. A partir de los 12 años telitromicina puede ser de elección en pacientes con alergia a beta-lactámicos o NAC indeterminada. Aunque las fluoroquinolonas no se prescriben en menores de 18 años, la experiencia en niños con enfermedades graves avala su seguridad y eficacia. Levofloxacino puede ser una opción cuando hay sospecha o evidencia de resistencias de neumococo a los macrólidos pues es efectiva contra neumococo y bacterias atípicas. Pocos estudios han analizado la duración óptima de la terapia antimicrobiana, 10 días de tratamiento con beta-lactámicos y 5 días con azitromicina son los mejor estudiados. Vilanova, (2014). 
Grupo de expertos en vacunación contra tos ferina, (2011). Ha quedado bien establecido que, en países con altas coberturas vacunales como México, la tos ferina es hoy en día una enfermedad de dos grupos poblacionales: los mayores de 10 años de edad y los niños pequeños no vacunados o parcialmente vacunados (infectados por el contacto con niños mayores, adolescentes y adultos). En los primeros, la morbilidad es significativa con casos graves ocasionales. En los segundos, las posibilidades de cuadros serios, hospitalización y muerte son altas. Así que la necesidad de vacunar a adolescentes y adultos ha quedado claramente definida. ¿Cómo llevarla a cabo en países como México? Los participantes en este consenso consideramos que la implementación descansa en tres pilares fundamentales, que se encuentran estrechamente relacionados:

\section{Educación.}

2. Estudios epidemiológicos.

\section{Estrategias definidas de introducción de la vacuna.}

Con frecuencia, los médicos no hacemos el diagnóstico de la enfermedad, 20-22 sobre todo en adolescentes y adultos donde el cuadro clínico es atípico. 37 Ante la creencia de que la enfermedad sólo afecta a niños, 23 se confunde el diagnóstico con múltiples entidades. 59 En otras palabras, si no existe conciencia del problema en el gremio médico, tampoco se visualizará la necesidad de la vacunación. Si los médicos no tenemos esta conciencia, tampoco la tendrán algunas autoridades de salud ni el público en general. Así que la educación del gremio médico y el personal de salud constituyen el terreno fértil donde la iniciativa de vacunación puede florecer. Este proceso de educación debe tener una participación multisectorial, que involucre autoridades de salud, asociaciones médicas e industria farmacéutica. Grupo de expertos en vacunación contra tos ferina, (2011).

La tos ferina, o pertussis, es una infección respiratoria causada por una bacteria llamada Bordetella pertussis. La ausencia de inmunidad permanente después de la infección natural, la protección limitada en el tiempo tras la vacunación y la dificultad en sospechar y confirmar el diagnóstico han dificultado el adecuado control de esta enfermedad. Los cuadros más graves, incluso mortales, ocurren en recién nacidos y lactantes de escasos meses de vida. Los macrólidos siguen siendo los antibióticos de elección, tanto para el tratamiento como para la profilaxis post exposición. Las 
nuevas estrategias de vacunación que incluyen la vacunación de los adolescentes, la embarazada y la estrategia del "nido" pueden contribuir a un mejor control de la enfermedad. Las vacunas combinadas con componentes acelulares para el antígeno pertussis han permitido, gracias a su seguridad y buena aceptación, alcanzar niveles adecuados de cobertura frente a tos ferina. Los datos de eficacia sugieren que es necesaria más investigación para desarrollar vacunas con una mejor y más duradera protección. Esso, (2014).

La sinusitis bacteriana aguda (SBA) es una complicación frecuente de la infección viral de vías respiratorias altas. Es un diagnóstico poco habitual al considerarse erróneamente una entidad de diagnóstico radiológico. El criterio fundamental para la selección del tratamiento es la actividad antineumocócica, porque S. pneumoniae, el agente etiológico más común, y la rinosinusitis neumocócica tiene menos tendencia a la resolución espontánea y mayor riesgo de complicaciones. Amoxicilina y amoxicilina-ácido clavulánico a "dosis altas" son de elección para la mayoría de SBA. Cefuroxima axetilo y cefpodoxima proxetilo son la mejor opción en niños con alergia no anafiláctica a penicilinas. A partir de los 12 años puede utilizarse cefditoren pivoxilo, una cefalosporina de tercera generación, más activa que cefpodoxima y cefuroxima. Otras cefalosporinas orales de tercera generación, como cefixima y ceftibuteno, muy activas frente a H. influenzae, apenas lo son frente a cepas de S. pneumoniae resistentes a la penicilina, por lo que no deben considerarse alternativa. Vilanova, (2014).

Antihistamínicos, Su única indicación sería en escolares y adolescentes que asocian una rinosinusitis alérgica. Deben retirarse si no mejoran en dos semanas. No hay estudios sobre homeopatía, acupuntura y hierbas chinas en la tos. No hay ninguna evidencia sobre el uso de humidificadores, vaporizadores, ionizadores y filtros, por lo que no están recomendados. En cuanto a remedios tradicionales, en la revisión de la Cochrane 2010 sobre el tema, la miel de trigo fue mejor que "ningún tratamiento" para el alivio sintomático de la tos, la resolución de la tos molesta y la mejoría de la calidad del sueño del niño. Sin embargo, no fue mejor que ningún tratamiento para mejorar la calidad del sueño de los padres. No hubo diferencias significativas entre la miel y el dextrometorfano ni el dextrometorfano y "ningún tratamiento" para todos los resultados. Recordemos que la miel no debemos utilizarla por debajo del año por el riesgo de botulismo. Quizás, en estos casos, sea útil la popular inhalación de cebolla. Ridao, (2012). 
En aquellos en los que la causa de la rinitis es intrínseca o desconocida, la acción terapéutica debe sustentarse en el empleo de medicamentos. Los expertos señalan que el tratamiento farmacológico debe adaptarse a los síntomas y a la gravedad de los mismos. En cuanto al tratamiento oral, los más utilizados son los antihistamínicos orales y los corticoides intranasales para controlar la congestión nasal. CuidatePlus, (2015).

La faringitis en los niños y adolescentes está causada por una gran variedad de agentes patógenos, con una frecuencia que varía según la edad, estación y área geográfica. La mayoría de las faringitis son víricas y la faringitis aguda por Streptococcus pyogenes solo supone un $10 \%$ del total de las faringitis en los adultos y alrededor del $30 \%$ en los niños. La penicilina se considera el tratamiento de elección, debido a su probada eficacia y seguridad, su bajo costo y su espectro reducido, que generará menos resistencias en otros patógenos. De hecho, no se han descrito nunca resistencias a este fármaco por parte de S. Pyogenes. La pauta recomendada de penicilina V oral (fenoximetilpenicilina potásica o benzatina) es de $25-50 \mathrm{mg} / \mathrm{kd} /$ día, cada 8-12 horas (sin que exista unanimidad científica en cuanto al número de dosis diarias de penicilina. De forma habitual se administra una dosis de penicilina de $250 \mathrm{mg}$ cada 12 horas durante 10 días en menores de 12 años y peso menor de $27 \mathrm{Kg}$ y una dosis de penicilina de $500 \mathrm{mg}$ cada 12 horas en los mayores de 12 años o peso mayor o igual a $27 \mathrm{Kg}$. AEPap, (2011).

La otitis es una infección del oído que por lo general causada por bacterias. Tratamiento sintomático de elección tras el diagnóstico es la analgesia. Suele ser suficiente ibuprofeno o paracetamol por vía oral a las dosis habituales. Si no hay respuesta y el dolor es muy intenso, debe plantearse la timpanocentesis. En el Tratamiento antibiótico o conducta expectante, los antibióticos se han administrado ampliamente en esta enfermedad con 2 fines: evitar las complicaciones y mejorar los síntomas. Tomando en consideración el patógeno más probable y su grado de resistencia a los antimicrobianos. En los niños con riesgo de mala evolución, en quienes se pretende cubrir todo el espectro de microorganismos probables, y también en los casos de fracaso terapéutico con amoxicilina, debe pautarse como primera elección amoxicilina-ácido clavulánico. Del Castillo, et al., (2012).

Bronquitis es la inflamación e irritación de la membrana mucosa de los bronquios. El tratamiento es sintomático y los antibióticos se emplean en casos seleccionados. Existe una variedad de medidas de 
soporte: Hidratación adecuada para fluidificar las secreciones, ofreciendo líquidos por vía oral con frecuencia. Permeabilidad nasal con suero fisiológico y aspirar secreciones. Antitérmicos si hay fiebre. No se recomienda el uso de antibióticos de manera rutinaria en niños diagnosticados de bronquitis aguda, ya que la mayoría de los casos son producidos por virus; además, se ha podido comprobar que no ejercen ningún beneficio sobre la tos, y no previenen ni disminuyen la severidad de las complicaciones bacterianas. Cansino, (2012).

Únicamente, estarían indicados en casos seleccionados. Cuando la tos se prolonga 10 días, podría estar indicado tratamiento antibiótico específico en los siguientes casos: si se sospecha tos ferina (azitromicina), infección por Mycoplasma pneumoniae (un macrólido) y en aquellos niños con enfermedad pulmonar crónica grave (fibrosis quística, displasia broncopulmonar, hipoplasia pulmonar, discinesia ciliar, aspiración crónica). Los broncodilatadores inhalados no están indicados de manera rutinaria, sólo en aquellos casos en los que se asocie broncoespasmo. Sin embargo, hay niños con hiperreactividad bronquial que presentan un mínimo e incluso no apreciable broncoespasmo a la exploración, pero que responden de manera espectacular al broncodilatador inhalado, con resolución de la tos. Cansino, (2012).

Bronquiolitis es la inflamación aguda de los bronquiolos debido a una infección de origen viral. El tratamiento, en la mayoría de los casos, consistirá en medidas de soporte para mantener unas adecuadas hidratación y oxigenación; los broncodilatadores inhalados pueden resultar beneficiosos para un grupo de pacientes. Cansino, (2012).

Junto con el aumento de la prevalencia de enfermedades respiratorias crónicas y Neuromusculares, surgen avances tecnológicos que permiten entregar prestaciones orientadas a mejorar la calidad y expectativa de vida de niños y adolescentes. No obstante, en estos pacientes, ya sea por exacerbaciones respiratorias recurrentes, causas sociales y de habitabilidad; e incluso cuando la evolución es estable, las hospitalizaciones de estancia prolongada son una realidad frecuente que requiere cuidados estandarizados. Muchos enfermos con compromiso primario o secundario de la bomba respiratoria son abordables con asistencia ventilatoria no invasiva (AVNI). En aquellos pacientes con mayor dependencia y riesgo por escasa o nula autonomía ventilatoria, ausencia de los mecanismos de protección glótica o inestabilidad de la vía aérea, la elección es la ventilación mecánica invasiva (VMI) establecida a través de una traqueostomía (TQT). Prado, et al., (2009). 


\section{Conclusiones.}

Las infecciones respiratorias agudas son un complejo grupo de enfermedades producidas por diferente etiología ya sea bacteriana, viral, etc., que afecta la estructura del aparato respiratorio a cualquier nivel. Se ubican entre las 10 principales causas de defunción en la población general, no solo están presentes en el adulto, sino también en la etapa de la niñez y adolescencia, por lo tanto es de vital importancia darle un manejo prioritario a estas patologías ya que son un problema de salud publica. Se calcula que en 2015 murieron 1,2 millones de adolescentes, es decir, más de 3000 al día, en su mayoría por causas prevenibles o tratables. Los adolescentes (edades entre los 10 y los 19 años) representan aproximadamente una sexta parte de la población mundial (1200 millones de personas). La adolescencia es considerada una etapa de buena salud, pero, es un periodo de gran interés ya que de él depende el desarrollo y la producción futura de los países, y siendo en este periodo donde se desarrollan conductas que incidirán en la carga global de enfermedad en los adultos. La pobreza e inequidad en la que viven muchos de los adolescentes, los lleva a la marginalización y la violencia y esto tiene implicancias en la salud, no solo en la adquisición de conductas de riesgo sino también en el acceso al sistema de salud, puesto que no son alcanzados por los programas de cuidados pediátricos ni los de adultos, tampoco cuentan con servicios de atención específicos para su edad, especialmente en el primer nivel de atención en donde se pueda promover estrategias de prevención y promoción focalizados a sus necesidades y en conjunto con otras instituciones comunitarias. En 2016 se publicó una observación sobre los derechos de los niños durante la adolescencia, se puso de relieve las obligaciones de los Estados de reconocer las necesidades de salud y de desarrollo específico de los adolescentes y las personas jóvenes, así como sus derechos, Es importante el fortalecimiento de los programas de educación en salud, el uso adecuado de antimicrobianos, la actividad física y la nutrición también ayuda a mejorar la salud antes de que los adolescentes se conviertan en padres. Es de gran importancia prevenir la enfermedad por medio de tratamientos, terapias respiratorias y programas de vacunación lo que permitirá disminuir en gran medida las tasas altas de mortalidad a causa de las IRA.

\section{Referencias bibliográficas.}

AEPap, (2011), Respirar para respirar, Grupo de Vías Respiratorias de la (AEPap), Recuperado de: http://www.respirar.org/images/pdf/grupovias/faringoamigdalitis2011.pdf 
Aldana, R., Coria, J., Bustos, C., Espinosa, L., Karam, B., (2001). Infecciones Respiratorias agudas en menores de 5 años, Práctica médica efectiva, 3(7).

Aleman, A., Colistro, V., Colomar, M., Cavalleri, F., Alegretti, M., Buglioli, M., (2018), Carga de enfermedad de los adolescentes en Uruguay y su comparación con la de América Latina y el Caribe, ARTIGOS, Ciencia Saúde Colectiva, Vol. 23, Núm. 9, pág. 2813-2820.

Camargo S., A. \& Gutiérrez D., D., (2010), Situación mundial y nacional de las enfermedades crónicas no transmisibles: un desafío para enfermería. Revista de enfermería. 2010, Volumen 13, Número 1, pp. 15-17.

Cansino C., Á., (2012), bronquitis y bronquiolitis, Pediatría Integral. Volumen XVI, Número 1, pág. 37-44, Recuperado de: https:/www.pediatriaintegral.es/numeros-anteriores/publicacion2012-01/bronquitis-y-bronquiolitis/

Cubanos, A., (2006). Pediatría, Colectivo de Autores, Tomo III, En A. Cubanos, Pediatría, Ciencias Médicas, La Habana, Cuba, pág. 538.

CuidatePlus, (2015). Rinitis tratamientos, síntomas e información en CuidatePlus, Recuperado de: http://www.cuidateplus.com/enfermedades/alergias/rinitis.html

Del Castillo, F., Baquero, F., de la Calle, T., López, M., Ruiz, J., Alfayate, S., Moraga, F., Cilleruelo, M. y Calvo, C., (2012). Documento de consenso sobre etiología, diagnóstico y tratamiento de la otitis media aguda, Asociación Española de Pediatría, Recuperado en: https://continuum.aeped.es/files/consensos/Nov_2012_Otitis\%20media\%20aguda.pdf

Domínguez, R., Tapia, E., Hernández, J., Castillo, IY., (2017). Edad y nivel educativo asociados al conocimiento sobre signos de alarma para infecciones respiratorias en madres adolescentes, Revista Cuidarte 8(2): 1628-37, http://dx.doi.org/10.15649/cuidarte.v8i2.395

Esso Arbolave, V., (2014), Actualización en tos ferina, Pediatría Integral, Volumen XVIII, Número 2, pág. 101-107.

Ferreira, E., Báez, R., Trejo, B., Ferreyra, L., Delgado, G., Lingdao, O., Mendoza, L., García, L., (2013). Infecciones respiratorias agudas en niños y signos de alarma identificados por padres y cuidadores en México, Salud Pública de México / vol. 55, suplemento 2 de 2013, pp. S307S313. 
Girard, G., (2009), Poverty and Inequity in Adolescent Health Care, Adolescent Medicine: State of the art Reviews 2009, Volumen 20, Número 3, pág. 887-899.

González, J., (2013), Las infecciones respiratorias agudas en el niño. Revista Cubana Pediatr. 2013, Volumen 85, Número 2, pp. 147-48.

Gonzalo de Liria, C., Méndez Hernández, M., (2012), Infecciones víricas del tracto respiratorio inferior, Pediatr Integral, Volumen XVI, Número 1, pág. 23-34.

Grupo de expertos en vacunación contra tos ferina, (2011). Consenso para el diagnóstico clínico y microbiológico y la prevención de la infección por Bordetella pertussis, Salud Pública de México, vol. 53, no. 1, pág. 57-65.

Hidalgo V., M., (2004). Atención Integral del adolescente, Revisión crítica, XVIII Congreso nacional de la Sociedad Española de Pediatría Extrahospitralaria y Atención Primaria. Pediatría Integral, 7 (especial): 76-84.

Lloyd, C., (2005). Crecer en el mundo: las transiciones cambiantes a la edad adulta en los países en desarrollo: National Academies Press, Washington.

Marès, J., (2014). Profilaxis antimicrobiana y postexposición, Pediatría Integral, Volumen XVIII, Número 2, pág. 75-88.

Ministerio de Salud y Protección Social. (2014). Programa Nacional de Prevención, Manejo y Control del IRA. Disponible en: https://www.minsalud.gov.co/sites/rid/Lists/BibliotecaDigital/RIDE/VS/PP/ET/PREVENCI ON-MANEJO-CONTROL-IRA-MENORES-5-ANOS-2015.pdf

OMS, (2018). Adolescentes: riesgos para la salud y soluciones, Organización Mundial de la Salud, Ginebra, Suiza, https://www.who.int/es/news-room/fact-sheets/detail/adolescents-healthrisks-and-solutions

OMS, (2016). Preventing disease through healthy environments: a global assessment of the burden of disease from environmental risks, Ginebra: Organización Mundial de la Salud. Disponible en: http://apps.who.int/iris/bitstream/10665/204585/1/9789241565196_eng.pdf?ua=1. 
OMS, (2015). Todas las mujeres, todos los niños. La estrategia mundial para la salud de la mujer, el niño y el adolescente (2016-2030), Organización Mundial de la Salud. Disponible en: http://www.who.int/maternal_child_adolescent/documents/wom-en-deliver-globalstrategy/es/

OMS, (2015). Neumonía, centro de prensa, Organización Mundial de la Salud, Recuperado de: http://www.who.int/mediacentre/factsheets/fs331/es/

OMS, (2005). Global Alliance Against Chronic Respiratory Diseases. Chronic respiratory diseases: a world where all people breathe freely, Organización Mundial de la Salud. Disponible en: http://www.who.int/gard/GARD_sign_up/en/.

Prado, F., Salinas, P., Zenteno, D., Vera, R., Suranyi, C., (2009). Recomendaciones prácticas para el cuidado hospitalario del niño/adolescente con necesidades especiales y dependencias tecnológicas respiratorias, Neumología pediátrica, pág. 51-64. Disponible en: http://www.neumologia-pediatrica.cl

Redondo M., R., (2008). La tos. Tos persistente. Pediatr Integral, 1: 29-36.

Ridao Redondo, M., (2012). Tos persistente, Pediatr Integral, Volumen XVI, Número 1, pág. 13-20.

Rodríguez, N., Martínez, V., Sarmiento, R., Medina, E., Hernández, L., (2013). Factores de riesgo para enfermedad respiratoria en población de 5 a 14 años de una Localidad de Bogotá, 20122013, Revista de Salud Publica, Journal of Public Health. 2013, 15(3).

Silva, B., Ferrada, C., Santolaya, M., (2012). Impacto de una intervención educativa en el conocimiento sobre uso adecuado de antimicrobianos en infecciones respiratorias en un grupo de adolescentes, Rev Chilena Infectol 2012, 29 (5): 499-503.

Toledo Rodríguez, I., Toledo Marrero, M., (2012). Neumonía adquirida en la comunidad en niños y adolescentes, Revista Cubana de Medicina General Integral, Volumen 28, Número 4, Pág. 712-724.

UNICEF, (2016). United Nations Children's Fund (UNICEF), Disponible en: https:/data.unicef.org/topic/adolescents/adolescent-demograph-ics/ 
Prevención frente la presencia de infecciones respiratorias que sufren los adolescentes

Vilanova, J., (2014). Guía práctica de utilización de antimicrobianos para el tratamiento de las infecciones bacterianas más prevalentes, Pediatría Integral, Volumen XVIII, Número 2, pág. 115-123.

Viner, R., Coffey, C., Mathers, C., Bloem, P., Costello, A., Santelli, J., Patton, G., (2011). 50-year Mortality Trends in Children and Young People: A study of 50 low-income, middle-income and high-income countries, Lancet 2011, 377 (9772): 1162-1174.

WHO, (1999). Programming for Adolescent Health and Development Report, World Health Organization. pp. 886-99.

Ziv, A., Boulet, J., Slap, G., (1999). Utilization of physician offices by adolescents in the United States, Pediatrics, 104: 35-42. 